\title{
When is lack of scientific integrity a reason for retracting a paper? A case study
}

Citation for published version (APA):

Fiedorowicz, J. G., Levenson, J. L., \& Leentjens, A. F. G. (2021). When is lack of scientific integrity a reason for retracting a paper? A case study. Journal of Psychosomatic Research, 144, [110412]. https://doi.org/10.1016/j.jpsychores.2021.110412

Document status and date:

Published: 01/05/2021

DOI:

10.1016/j.jpsychores.2021.110412

Document Version:

Publisher's PDF, also known as Version of record

Document license:

Taverne

Please check the document version of this publication:

- A submitted manuscript is the version of the article upon submission and before peer-review. There can be important differences between the submitted version and the official published version of record.

People interested in the research are advised to contact the author for the final version of the publication, or visit the DOI to the publisher's website.

- The final author version and the galley proof are versions of the publication after peer review.

- The final published version features the final layout of the paper including the volume, issue and page numbers.

Link to publication

\footnotetext{
General rights rights.

- You may freely distribute the URL identifying the publication in the public portal. please follow below link for the End User Agreement:

www.umlib.nl/taverne-license

Take down policy

If you believe that this document breaches copyright please contact us at:

repository@maastrichtuniversity.nl

providing details and we will investigate your claim.
}

Copyright and moral rights for the publications made accessible in the public portal are retained by the authors and/or other copyright owners and it is a condition of accessing publications that users recognise and abide by the legal requirements associated with these

- Users may download and print one copy of any publication from the public portal for the purpose of private study or research.

- You may not further distribute the material or use it for any profit-making activity or commercial gain

If the publication is distributed under the terms of Article $25 \mathrm{fa}$ of the Dutch Copyright Act, indicated by the "Taverne" license above, 
Discussion

\title{
When is lack of scientific integrity a reason for retracting a paper? A case study
}

\author{
Jess G. Fiedorowicz ${ }^{\mathrm{a}, *, 1}$, James L. Levenson ${ }^{\mathrm{b}, 2}$, Albert F.G. Leentjens ${ }^{\mathrm{c}, 3}$

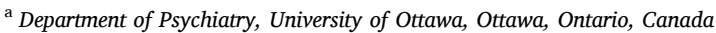 \\ ${ }^{\mathrm{b}}$ Department of Psychiatry, Virginia Commonwealth University, Richmond, Virginia, USA \\ ${ }^{\mathrm{c}}$ Department of Psychiatry, Maastricht University Medical Centre, Maastricht, the Netherlands
}

\section{A R T I C L E I N F O}

\section{Keywords}

Blinding

Ethical reflection

Homeopathy

Randomized control trial

Retraction

Scientific Misconduct

\begin{abstract}
A B S T R A C T
Objective: The journal received a request to retract a paper reporting the results of a triple-blind randomized placebo-controlled trial. The present and immmediate past editors expand on the journal's decision not to retract this paper in spite of undisputable evidence of scientific misconduct on behalf of one of the investigators. Methods: The editors present an ethical reflection on the request to retract this randomized clinical trial with consideration of relevant guidelines from the Committee on Publication Ethics (COPE) and the International Committee of Medical Journal Editors (ICMJE) applied to the unique contextual issues of this case.

Results: In this case, scientific misconduct by a blinded provider of a homeopathy intervention attempted to undermine the study blind. As part of the study, the integrity of the study blind was assessed. Neither participants nor homeopaths were able to identify whether the participant was assigned to homeopathic medicine or placebo. Central to the decision not to retract the paper was the fact that the rigorous scientific design provided evidence that the outcome of the study was not affected by the misconduct. The misconduct itself was thought to be insufficient reason to retract the paper.

Conclusion: Retracting a paper of which the outcome is still valid was in itself considered unethical, as it takes away the opportunity to benefit from its results, rendering the whole study useless. In such cases, scientific misconduct is better handled through other professional channels.
\end{abstract}

\section{Introduction}

On November 26, 2019, we received a formal request from Alan Henness ${ }^{4}$ to consider retraction of a 2004 publication based on a public admission of unethical behavior by one of the nine homepaths administering the treatment with the insinuation of possible involvement of others. The relevant paper was a randomized controlled trial (RCT) on the efficacy of homeopathic treatment for chronic fatigue syndrome by lead author Elaine Weatherley-Jones [1]. As part of the study design, the patient, homeopaths, and data analyst were blind to group assignment. The integrity of the blind was assessed and reported. Both patients and homeopaths were unable to reliably predict treatment group. The rigor of blinding efforts was one of the strengths of the study.

As a brief summary of the study, 103 people with chronic fatigue syndrome were randomized to homeopathic medicine or placebo. The medicine was provided by a homeopathic pharmacy, approximately 300 miles away and with no contact between the homeopaths and the pharmacy. Homeopathic medicines and placebo were prepared identically and had identical appearance and taste with one exception: the placebos did not contain the indicated source material as individually prescribed by the homeopath. At study close, results were available for 43 participants in each group for a completer's analysis on the primary outcome measures, which consisted of the five subscales of the Multidimensional Fatigue Inventory (MFI). The study was conducted before

DOI of original article: https://doi.org/10.1016/S0022-3999(03)00377-5.

* Corresponding author.

E-mail address: jess-fiedorowicz@uiowa.edu (J.G. Fiedorowicz).

1 Editor (2018-Present), Journal of Psychosomatic Research.

2 Former Editor (2010-2017), Editorial Advisory Board (2018-Present), Journal of Psychosomatic Research.

${ }^{3}$ Former Editor (2011-2017), Editorial Advisory Board (2018-Present), Journal of Psychosomatic Research.

4 Permission to report by name. 
registration in a publicly accessible trial register was a requirement of the International Committee of Medical Journal Editors (ICMJE) and this study wasn't registered and cites no prior published protocol. There was no adjustment of the threshold of significance to manage Type I error with multiple comparisons for the five co-primary outcomes. Only one of the five primary outcomes, the MFI general fatigue scale showed a statistically significant difference between groups with a 1.35 point greater improvement for the homeopathic medicine group $(p=0.04)$, short of the 3 points determined by the project steering committee to be clinically significant. Between group differences in the proportion of patients showing clinically significant improvements based on this threshold were also not statistically significant. The paper nonetheless concluded that there was "weak but equivocal evidence that the effects of homeopathic medicine are superior to placebo" [1].

The complaint arises from a talk given by Dr. Clare Relton, a homeopath involved in the trial, at a conference held by the Homeopathy Research Institute between the 14th and 16th of June 2019 [3]. In this talk, Dr. Relton discusses how she found a "cunning way of circumventing the blinding" as transcribed (JGF) in the following:

"So, uhm, after about six months of this we started working out. There was a cunning way (laughs) of circumventing the blinding and we worked out, well if we give them all a dose of carcinosin, they're going to have some reaction: there's going to be a dream, there's going to be some change and if when they come back at the second appointment they haven't changed, then we know they're on placebo. So, don't bother doing all that trying to find the right remedy; just use all your other amazing skills you have as a homeopath: the deep listening we have, the deep understanding of what we know about what's toxic in our systems, about diet and counseling.

So that's what we did. Because we're homeopaths. We're trained to treat people. I'm not trained to be deceiving people. That's what I do, that's what I did then; that's what all my colleagues did."

In the video, Dr. Relton describes contacting the pharmacy after the consultation. In a personal communication, lead and corresponding author Dr. Weatherley-Jones confirms that this is an inaccurate description of the study protocol. As part of the study design, the homeopaths would contact her and she would fax the prescription request to the dispensing homeopathic pharmacy, who held the blinding codes. There was no direct contact between the homeopaths and the pharmacies, consistent with the published description [1]. Carcinosin could be prescribed as part of the study protocol, and, by study protocol, if prescribed would be the sole medication at any given visit. Patients in the placebo group would have received a placebo for any carcinosin prescription from the dispensing pharmacy.

\section{Methods}

In follow-up to the complaint, the Associate Editors, European Association of Psychosomatic Medicine pages Editor, the two immediate past Editors, and current Editor reviewed the complaint, the article, and Dr. Relton's conference presentation. We reached out to the corresponding author of the RCT, Dr. Elaine Weatherley-Jones, and other members of the study team for additional information, clarification, and confirmation of the accuracy of details related to study procedures. The editorial team conducted an ethical reflection on the request to retract this randomized clinical trial. As recommended by the ICMJE, we considered relevant guidelines from the Committee on Publication Ethics (COPE) and applied them to the unique contextual features of this case.

\section{Results}

We found the presentation by Dr. Relton disturbing on multiple grounds. This admission of unethical behavior calls her scientific integrity into question. The premise for her actions rests on an errant assumption widespread among clinicians, based on anecdotal experience, that one possesses an ultimate knowledge of what works and doesn't work without the need for rigorous study. The history of medicine, unfortunately, has been littered by countless treatments that practitioners believed in and dispensed, only to be later found not beneficial or even harmful [4]. This underscores the importance of rigorous study for treatments where equipoise exists in the scientific community, as it arguably did for the use of homeopathy for chronic fatigue syndrome. Dr. Relton likely did not hold that equipoise herself, but if she had ethical concerns about the study, the appropriate action would have been to not participate in it. Instead, she purports to have enlisted colleagues to deliberately and systematically undermine the study.

In watching the presentation, the purpose of this admission seemed to be to discount the results of a rigorous but essentially negative study in the context of promoting her own ideas related to trial design. While we cannot know for certain that her motivation was to discount the results of this study, what she said clearly seeks to undermine the credibility of a trial whose results challenged her firmly held but untested beliefs about the benefit of a treatment that she had high allegiance to. Regardless of her intent or what actually happened during the trial, Dr. Relton's presentation is ipso facto evidence of either an admitted prior ethical breach or is itself an ethical breach for the following reasons. Either she indeed undermined an ambitious effort to study the efficacy of homeopathy for chronic fatigue syndrome, negating the work of all other investigators, study staff, and participants involved in the study as well as the investment of the public, or she is conducting a late and inappropriate attack on the study's credibility. Her presentation certainly warrants formal censure from the scientific community, and this paper may contribute to that. Despite this clear indictment, after discussing and considering the complaint of Mr. Henness for several months, we ultimately decided not to retract the paper.

\section{Discussion}

In this discussion, we want to expand on how we came to this decision. Editors should consider retraction of a paper a serious matter. Retractions may impact and damage the reputation and career of researchers, even that of co-authors who are not blameworthy [2]. It may also damage the reputation of institutions and journals. The most common reasons for retracting a paper are scientific misconduct and mistakes $[5,6]$. In order to help editors with their decision to retract a paper, guidelines for retracting papers have been established, such as the COPE retraction guideline [7]. The ICMJE statement on Scientific Misconduct, Expressions of Concern, and Retraction recommends following COPE procedures [8]. Such guidelines often either don't mention or are not specific about policies for retraction on ethical issues [2]. While clearer guidance might at times be valuable, these decisions often ultimately require considerable consideration of context, as our case example nicely illustrates. The COPE retraction guidelines suggest editors should consider retracting a paper if there is clear evidence that the findings are unreliable as a result of that misconduct, whether due to error or fabrication [7]. The COPE guidelines additionally state that retraction is usually not appropriate if the main findings of the work are still reliable [7], as we have argued in this case. Additional reasons for retraction of a paper, as mentioned by the COPE retraction guidelines are if findings have been previously published without proper crossreferencing (double or redundant publication), if it constitutes plagiarism, or if it reports unethical research. There is no further definition of 'unethical research'.

The editors want to highlight two issues in relation to their decision not to retract this paper: 1) the importance of a rigorous design as protection against scientific misconduct, and 2) the question of when unethical scientific conduct is in itself enough reason for retracting a paper. 


\subsection{The importance of a rigorous study design}

The rigorous study design, in which blinding was explicitly assessed and reported, is what 'saved' this study in the end. Weatherley-Jones and colleagues assessed the integrity of the blind with both patients and homeopaths and reported the results. The purported intervention aimed at circumventing the blind was not effective and thus presumably did not alter the results. Homeopaths were not able to identify group assignment better than chance. In fact, they didn't even come close ( $\kappa=$ $0.07, p=0.60$ ). This is not entirely surprising, as the method by which Dr. Relton proposed that they circumvented the blind is itself somewhat dubious. It rests on another assumption, that all patients would have a similar and predictable reaction to a given treatment. This ignores wellestablished individual variation in response to treatments, which should be even more variable for a treatment diluted to a homeopathic dose. While it is also possible that the homeopaths could have lied about their thoughts about group assignment, this would further undermine Dr. Relton's credibility and constitute collective unethical behavior by the participating homeopaths. In her reported effort to treat everyone with carcinosin, she was also contradicting her stated goal of individually treating every patient. Without the assessment of blinding, the authors could not have reliably demonstrated that the unethical behavior by one of their researchers did not affect the blinding, and consequently did not affect treatment outcome. In that case, following the COPE guidelines, there would have been no other option than retract the paper. This underscores the importance of a rigorous study design.

The assessment of the integrity of the blind is infrequently reported [9]. An estimated 4 in 10 trials assess risk of unblinding but fail to report this in trial publication [10]. While there is some controversy about asssessing the integrity of the blind, particularly where unblinding may occur due to therapeutic effects and misinterpretation thereof [11], statistical techniques can estimate the likelihood of this. Reporting on the integrity of the blind has merit and is especially valuable when dealing with subjective outcomes for which there is a greater risk of bias due to any unblinding [12]. Un-blinded assessors of subjective binary outcomes may exaggerate odds ratios by an average of $36 \%$ [13]. Subjective outcomes are frequently used in studies that fall within this journal's scope, at the interface of psychology and medicine. We recommend assessing the integrity of the blind for any clinical trial, particularly those utilizing subjective outcomes akin to the primary outcomes of the Weatherley-Jones et al. study in question.

\subsection{Ethical misconduct}

In the COPE guidelines, 'unethical research' is given as an alternative reason for retracting a paper. In our case, the study followed the design of a standard placebo-controlled randomized clinical trial and is not considered unethical. The intention was to assess the efficacy of homeopathic treatment in patients with chronic fatigue syndrome. The efficacy of this treatment in this patient group is not established, and no effective treatment was withheld from patients. Apart from the intention of 'circumventing the blind', there is another unethical aspect to the behavior of Dr. Relton, namely the fact that patients were systematically subject to an intervention (carcinosin administration) that was not part of the original research protocol and to which they did not consent as part of the study. Although the systematic administration of carcinosin was not part of the study protocol, it was administered only to patients taking part in the study, and because they took part in the study. Presumably, these patients were not properly informed, or maybe even misinformed, about the rationale of a double-blind trial design and/or the true reason for administrating carcinosin. Apparently, 'deep listening and deep understanding' does not necessarily need to be accompanied by an honest and open attitude towards patients that participate in research. Dr. Relton stated in her lecture 'I'm not trained to be deceiving people', but that is exactly what she did. Not only did she deceive patients, but also the researchers and study leaders that she is supposed to collaborate with as a colleague. The question is whether such unethical conduct is itself enough reason to retract the paper. The editors decided that this was not the case. Retracting the paper would imply that it would not be part of the scientific body of evidence anymore and all efforts of researchers and patients would have been useless. Since the results of the study were not likely meaningfully impacted by the misconduct of one of its researchers and still stands, retracting the paper could in this respect also be seen as unethical. If the findings of the study are still valid, there is no benefit in retracting the paper. In such cases, scientific conduct of one or more of its researchers should be addressed through different channels, such as through professional associations, employers or sponsors.

\subsection{Sanctions}

One of the questions that editors struggle with is what their role and responsibilities are to address misconduct outside the scope of their journal. In earlier guidelines editors were advised to follow a proactive approach and even apply sanctions if they thought this was appropriate [14]. Such sanctions would depend on the severity of the misconduct, and could - apart from retracting the paper - include informing the researcher's employer, the funding body or even the General Medical Council (or equivalent). It could also include refusal to accept future submissions from the individual, unit or institution responsible for the misconduct for a stated period. Updated guidelines do not mention such sanctions anymore, possibly due to privacy issues and legal restrictions [15]. The authors are of the opinion that in case the misconduct was not conducted by or on behalf of the principal investigator - as is the case here -, the initiative for further action should lie with them. Not only is the principal investigator the one that was deceived, but they are in a better position to report the misconduct to the institution and funding body. If the principal investigator is responsible for the misconduct, the editor is probably the only one that can initiate further action, in which case the researcher's institution should be informed and requested to take appropriate action. In this case, the complainant had already contacted the University of Sheffield. An email dated 25 February 2020 from the Research Ethics \& Integrity Manager for Research Services at The University of Sheffield relayed their decision that "it would not be appropriate for the University of Sheffield to undertake a research misconduct investigation of the allegation against Dr. Relton, since she is not a current member of University staff, nor was she a member of staff at the time of the clinical trial in question." Decisions related to the concerns about the reliability of the published research finding were deferred to the Journal of Psychosomatic Research, which we have detailed in this report.

\section{Conclusion}

The present and past editors of this journal wanted to expand on how they reached the decision not to retract a paper of a study in which there is evidence of scientific misconduct of one of the participating researchers. Central to this decision was the fact that the rigorous scientific design provided evidence that the outcome of the study was not affected by the misconduct. The misconduct in itself was considered insufficient grounds to retract the paper. In fact, retracting a paper of which the outcome is still valid was considered to be unethical, as it takes away the opportunity to benefit from any knowledge provided by its results, rendering the whole study useless. In such cases, scientific misconduct is better handled through other professional channels.

\section{Acknowledgements}

The authors would like to thank the Associate Editors and Editorial Board Members who participated in this ethical discussion: Peter Henningsen, Elspeth Guthrie, Antonina Mikocka-Walus, Cédric Lemogne, Ulrike Ehlert, Bernd Löwe, and Dimitry Davydow. 


\section{References}

[1] E. Weatherley-Jones, J.P. Nicholl, K.J. Thomas, G.J. Parry, M.W. McKendrick, S. T. Green, et al., A randomised, controlled, triple-blind trial of the efficacy of homeopathic treatment for chronic fatigue syndrome, J. Psychosom. Res. 56 (2) (2004) 189-197.

[2] W. Bulow, T.E. Godskesen, G. Helgesson, S. Eriksson, Why unethical papers should be retracted, J. Med. Ethics (2020), 106140. In press.

[3] Homeopathy Research Institute Research Conference, Accessed on 25 Dec 2020. Available from: https://www hrilondon2019.org/films/\#clip=eitxmhl1ilss, 2019.

[4] H. Benson, D.P. McCallie Jr., Angina pectoris and the placebo effect, N. Engl. J. Med. 300 (25) (1979) 1424-1429.

[5] G. Li, M. Kamel, Y. Jin, M.K. Xu, L. Mbuagbaw, Z. Samaan, et al., Exploring the characteristics, global distribution and reasons for retraction of published articles involving human research participants: a literature survey, J. Multidiscip. Healthc. 11 (2018) 39-47.

[6] E. Deculllier, H. Maisonneuve, Correcting the literature: improvement trends seen in contents of retraction notices, BMC Res. Notes. 11 (1) (2018) 490.

[7] COPE Council, COPE Guidelines: Retraction Guidelines, Available from: htt ps://publicationethics.org/retraction-guidelines, 2019.

[8] ICMJE, Scientific Misconduct, Expressions of Concern, and Retraction, Accessed on 1 Jan 2021. Available from: http://www.icmje.org/recommendations/browse/p ublishing-and-editorial-issues/scientific-misconduct-expressions-of-concern-andretraction.html.

[9] S. Bello, H. Moustgaard, A. Hrobjartsson, The risk of unblinding was infrequently and incompletely reported in 300 randomized clinical trial publications, J. Clin. Epidemiol. 67 (10) (2014) 1059-1069.

[10] S. Bello, H. Moustgaard, A. Hrobjartsson, Unreported formal assessment of unblinding occurred in 4 of 10 randomized clinical trials, unreported loss of blinding in 1 of 10 trials, J. Clin. Epidemiol. 81 (2017) 42-50.

[11] A. Crisp, Blinding in pharmaceutical clinical trials: an overview of points to consider, Contemp. Clin. Trials. 43 (2015) 155-163.

[12] J. Savovic, H.E. Jones, D.G. Altman, R.J. Harris, P. Juni, J. Pildal, et al., Influence of reported study design characteristics on intervention effect estimates from randomized, controlled trials, Ann. Intern. Med. 157 (6) (2012) 429-438.

[13] A. Hrobjartsson, A.S. Thomsen, F. Emanuelsson, B. Tendal, J. Hilden, I. Boutron, et al., Observer bias in randomised clinical trials with binary outcomes: systematic review of trials with both blinded and non-blinded outcome assessors, BMJ. 344 (2012), e1119.

[14] Committee On Publication Ethics, The COPE report 1999. Guidelines on good publication practice, Fam. Pract. 17 (3) (2000) 218-221.

[15] COPE Council, General Approach to Publication Ethics for the Editorial Office, Accessed on 14 February 2021 Available from: https://publicationethics.org/reso urces/flowcharts/general-approach-publication-ethics-editorial-office. 